Pedro Affonso Duarte Hartung ${ }^{1}$ Ekaterine Valente Karageorgiadis ${ }^{1}$

\title{
A REGULAÇÃO DA PUBLICIDADE DE ALIMENTOS E BEBIDAS NÃO ALCOÓLICAS PARA CRIANÇAS NO BRASIL
}

The regulation of food and non-alcoholic beverage advertising to children in Brazil

${ }^{1}$ Universidade de São Paulo. São Paulo/SP, Brasil.

Correspondência: Ekaterine Valente Karageorgiadis.E-mail: ekaterine.karageorgiadis@usp.br.

Recebido em: 24/06/2016. Aprovado em: 31/10/2016. 


\section{RESUMO}

O presente artigo tem como objeto a compreensão da regulação da publicidade infantil de alimentos e bebidas não alcoólicas no Brasil. Entende-se que essa discussão deve ser contextualizada no âmbito mais abrangente do direcionamento de publicidade de qualquer produto, serviço ou marca ao público menor de 12 anos de idade, tendo em vista que a publicidade de alimentos e bebidas é uma espécie de prática comercial considerada abusiva e, portanto, ilegal pelas normas brasileiras e por recomendações de organismos internacionais. A publicidade, ao se dirigir diretamente à criança, utiliza-se de sua hipervulnerabilidade, em função de seu desenvolvimento inconcluso, para persuadi-la ao consumo, violando direitos assegurados pela legislação, como o direito ao respeito que compreende a inviolabilidade física, psíquica e moral. Especificamente, a publicidade infantil de produtos alimentícios e bebidas não alcoólicas com baixos valores nutricionais, além de se utilizar da vulnerabilidade infantil, impacta diretamente o aumento das taxas de obesidade e sobrepeso infantis, tornando-se, assim, um problema de saúde pública importante a ser regulado. No Brasil, a regulação dessa atividade comercial ocorre dentro do contexto amplo da restrição do direcionamento da comunicação mercadológica às crianças, a qual vem sendo discutida intensamente em diversos âmbitos do Estado, inclusive por meio de ações judiciais que geraram histórico precedente no Superior Tribunal de Justiça, considerando abusiva e ilegal tal prática.

\section{Palavras-Chave:}

Alimentos; Bebidas Não Alcoólicas; Criança; Publicidade Infantil; Regulação.

\section{ABSTRACT}

The objective of this present article is to understand the regulation of food and non-alcoholic beverage advertising aimed at children in Brazil. It is argued that this discussion must be contextualized within the broader debate on advertising that targets children of less than 12 years of age, of any product, service or brand, given that the advertising of food and drinks to children is a species of the broader commercial practice of advertising, which is considered abusive and therefore illegal under Brazilian rules and by the recommendations of international organizations. Advertising directly to children utilizes their hyper-vulnerability and their unfinished development to persuade them to consume, violating their rights guaranteed by law, such as the right to respect comprising physical, mental and moral inviolability. Specifically, advertising of food and non-alcoholic beverages with low nutritional value to children, in addition to leveraging children's vulnerability, directly impacts increasing rates of childhood and weight, therefore becoming an important public health issue to be regulated. In Brazil, the regulation of this commercial activity takes place within the broader context of restricting marketing communication directed at children under 12 years of age,, which has been discussed extensively at various state levels, including through lawsuits that generated a historical precedent in the Brazilian Superior Court of Justice, which considered ins his decision this practice to be abusive and, therefore, illegal.

\section{Keywords:}

Advertising to Children; Children; Foods; Non-Alcoholic Beverages; Regulation. 


\section{Introdução}

A publicidade de alimentos e bebidas direcionada às crianças no Brasil encontra-se localizada em um amplo cenário nacional e internacional, referente não somente ao impacto dessas estratégias nos hábitos alimentares de crianças e no crescimento das taxas de obesidade e sobrepeso infantis, como também à discussão global acerca da vulnerabilidade da criança e da violação de seus direitos em função da publicidade de qualquer produto ou serviço dirigida a ela.

Crianças e adolescentes - indivíduos de até 12 anos de idade incompletos e entre 12 e 18 anos de idade ${ }^{1}$, respectivamente - foram reconhecidos como pessoas em um processo peculiar e inconcluso de desenvolvimento biológico, cognitivo e emocional, o que lhes confere um status jurídico especial de proteção e cuidado.

A doutrina de proteção integral à criança e ao adolescente foi positivada de forma exemplar no socialmente comemorado artigo 227 da Constituição Federal de $1988(\mathrm{CF} / 88)^{2}$. A pressão popular durante a Constituinte de 1987 e 1988 permitiu que os direitos fundamentais de crianças e adolescentes fossem constitucionalizados, inclusive os direitos à saúde e à alimentação, além do direito à proteção contra toda forma de exploração, violência, crueldade e opressão.

Contudo, apesar das garantias legais conquistadas no Brasil, o desenvolvimento dos meios de comunicação eletrônicos e digitais, sobretudo televisão e internet, transformou as experiências de infância em todo o mundo, permitindo um cenário preocupante de desconsideração de suas peculiaridades, conforme afirma Neil Postman ao analisar o desaparecimento da infância com o advento das mídias de comunicação de massa ${ }^{3}$.

Não são somente mensagens informacionais ou conteúdos de entretenimento que os meios de comunicação veiculam. A atual sociedade de hiperconsumo e seus agentes, forjados pela crescente industrialização, pela necessidade de escoamento da produção excedente e pelo estímulo à supra-satisfação das necessidades,

\footnotetext{
${ }^{1}$ Artigo $2^{\circ}$, do Estatuto da Criança e do Adolescente (ECA). BRASIL. Lei n. 8.069, de 13 de julho de 1990. Dispõe sobre o Estatuto da Criança e do Adolescente e dá outras providências. Disponível em: <http://www.planalto. gov.br/ccivil_03/leis/L8069.htm>. Acesso em: 31 jan. 2017. Para Convenção dos Direitos da Criança da Organização das Nações Unidas (ONU), crianças são todas as pessoas até 18 anos de idade. BRASIL. Decreto n. 99.710, de 21 de novembro de 1990. Promulga a Convenção sobre os Direitos da Criança. Disponível em: < http://www.planalto.gov.br/ccivil_03/decreto/1990-1994/D99710.htm>. Acesso em: 31 jan. 2017.

2“Art. 227. É dever da família, da sociedade e do Estado assegurar à criança, ao adolescente e ao jovem, com absoluta prioridade, o direito à vida, à saúde, à alimentação, à educação, ao lazer, à profissionalização, à cultura, à dignidade, ao respeito, à liberdade e à convivência familiar e comunitária, além de colocá-los a salvo de toda forma de negligência, discriminação, exploração, violência, crueldade e opressão. (Redação dada Pela Emenda Constitucional $n^{\circ} 65$, de 2010). § $1^{\circ} 0$ Estado promoverá programas de assistência integral à saúde da criança, do adolescente e do jovem, admitida a participação de entidades não governamentais, mediante políticas específicas e obedecendo aos seguintes preceitos.". BRASIL. Constituição da República Federativa do Brasil de 1988. Disponível em: <http://www.planalto.gov.br/ ccivil_03/constituicao/constituicaocompilado.htm>. Acesso em: 31 jan. 2017. ${ }^{3}$ POSTMAN, N. O desaparecimento da infância. São Paulo: Granphia, 1994.
} 
utilizam-se igualmente das mídias de comunicação (eletrônicas e digitais) para persuadir e seduzir indivíduos para o consumo de seus produtos e serviços, mesmo que estes não sejam realmente úteis ou necessários ou, ainda, realmente desejados. Ainda mais, tal sociedade, conforme entende o sociólogo Gilles Lipovetsky ${ }^{4}$, fundamenta-se em provocar anseios materiais impossíveis de serem alcançados, o que gera uma constante angústia, que, por sua vez, cria de forma cíclica novos desejos de compras e, também, novas insatisfações. Segundo Lipovetsky, a atual sociedade de hiperconsumo possibilita o advento do homo consumericus.

A ações de publicidade ou de comunicação mercadológica ${ }^{5}$ - nas mais diferentes variações, como anúncios impressos, comerciais televisivos, spots de rádio e banners na internet, embalagens, promoções, merchandising e product placement - fazem parte de forma quase indissociável do cotidiano de todas as pessoas, especialmente das crianças, que são um alvo preferencial, devido a sua vulnerabilidade e ao consumo constante e habitual que fazem de todas as mídias.

Direcionar publicidade à criança ${ }^{6}$ permite que produtos alimentícios, especialmente aqueles produzidos por grandes empresas que possuem recursos financeiros para desenvolver estratégias de marketing, sejam amplamente veiculados via ações de convergência, com narrativas transmídias, - ou seja, por meio do uso integrado de diferentes meios, estratégias e fluxos de conteúdos em múltiplos suportes midiáticos ${ }^{7}$.

O presente artigo busca a reflexão de que a regulação do direcionamento às crianças de publicidade de alimentos e bebidas deve ser inserida em uma discussão ampliada sobre os impactos da publicidade infantil de qualquer produto ou serviço nos direitos historicamente consolidados de crianças no Brasil e no mundo, inclusive nos direitos à saúde e à alimentação.

Inicialmente será analisado o relacionamento atual da criança brasileira com a publicidade infantil, bem como suas características e impactos, para, em seguida, detalhar o tratamento no âmbito global, regional e nacional da regulação da

\footnotetext{
${ }^{4}$ LIPOVETSKY, G. A felicidade paradoxal: ensaios sobre a sociedade de hiperconsumo. São Paulo: Companhia das Letras, 2006.

${ }^{5}$ Apesar do uso corrente do termo "publicidade" para determinar a prática de se veicular qualquer produto, serviço ou marca, inclusive pelo próprio Código de Defesa do Consumidor (CDC), Lei 8.078 de 1990, o termo "comunicação mercadológica ou comercial" é utilizado amplamente pelas teorias dos estudos de comunicação para desenhar de forma mais precisa a amplitude dessas práticas. No presente artigo, serão adotados os termos publicidade e comunicação mercadológica como sinônimos, para contemplar tanto o fenômeno jurídico como o social. BRASIL. Lei n. 8.078, de 11 de setembro de 1990. Dispõe sobre a proteção do consumidor e dá outras providências. Disponível em: <http://www.planalto.gov.br/ccivil_03/leis/L8078compilado.htm>. Acesso em: 31 jan. 2017.

${ }^{6}$ Será abordado somente o relacionamento da criança, e não dos adolescentes, com a publicidade, tendo em vista que o público com menos de 12 anos de idade é o mais vulnerável e suscetível às pressões comercias, conforme será apresentado ao longo deste artigo.

${ }^{7}$ JENKINS, H. Cultura da convergência: a colisão entre os velhos e novos meios de comunicação. São Paulo: Ed. Aleph, 2008.
} 
publicidade infantil de alimentos e bebidas, em razão dos seus impactos à saúde. Por fim, será dado o contexto regulatório existente atualmente no Brasil.

\section{A publicidade infantil e a hipervulnerabilidade das crianças}

A criança brasileira é uma das que mais assiste a televisão no mundo, com uma média de 5 h35min por $\operatorname{dia}^{8}$. Dados do Ibope Media apontam, ainda, que $96 \%$ da população brasileira tem o hábito de assistir à TV aberta e que, com o crescimento de $10 \%$ no consumo de TV paga pela população, este meio ganhou mais força. Além disso, 77\% das crianças e adolescentes de 9 a 17 anos são usuários da internet ${ }^{9}$. É justamente o uso massivo dos meios de comunicação e das novas tecnologias de informação e comunicação por crianças e adolescentes que é responsável por atrair anunciantes para tais espaços.

A publicidade infantil compreende toda e qualquer atividade de comunicação comercial para a divulgação de produtos e serviços, independentemente do suporte ou do meio utilizado. Destaca-se que comunicação mercadológica dirigida às crianças difere de comunicação mercadológica de produtos ou serviços infantis. Isso porque a primeira modalidade não diz respeito a nenhum tipo específico de produto ou serviço, mas sim é caracterizada pelo apelo comercial direto às crianças. Tal característica pode ser identificada pelo uso de atributos destinados a conquistar a atenção infantil para o consumo, como é o caso de trilhas sonoras cantadas por crianças e do uso de personagens infantis ${ }^{10}$.

Sobre o entendimento que a criança tem da publicidade, um dos estudos internacionais mais relevantes acerca da temática ${ }^{11}$ concluiu, após extensa revisão bibliográfica, que as crianças não têm condições de compreender as mensagens

\footnotetext{
${ }^{8}$ TEMPO de crianças e adolescentes assistindo TV aumenta em 10 anos. Disponível em: <http:// criancaeconsumo.org.br/noticias/tempo-diario-de-criancas-e-adolescentes-em-frente-a-tv-aumenta-em-10anos/>. Acesso em: 12 jun. 2016.

INSTITUTO BRASILEIRO DE OPINIÃO E ESTATÍSTICA - IBOPE. Mediabook Brasil, Abertura, 2013. Disponível em: <http://www.mediabook.ibope.com/pais/brasil/2013/abertura/destaque>. Acesso em: 19 fev. 2017.

${ }^{10}$ Segundo o artigo $2^{\circ}$ da Resolução 163 do Conselho Nacional dos Direitos da Criança e do Adolescente (Conanda), “considera-se abusiva, em razão da política nacional de atendimento da criança e do adolescente, a prática do direcionamento de publicidade e de comunicação mercadológica à criança, com a intenção de persuadi-la para o consumo de qualquer produto ou serviço e utilizando-se, dentre outros, dos seguintes aspectos: I - linguagem infantil, efeitos especiais e excesso de cores; II - trilhas sonoras de músicas infantis ou cantadas por vozes de criança; III - representação de criança; IV pessoas ou celebridades com apelo ao público infantil; $V$ - personagens ou apresentadores infantis; VI - desenho animado ou de animação; VII - bonecos ou similares; VIII - promoção com distribuição de prêmios ou de brindes colecionáveis ou com apelos ao público infantil; e IX - promoção com competições ou jogos com apelo ao público infantil.". CONSELHO NACIONAL DOS DIREITOS DA CRIANÇA E DO ADOLESCENTE. Resolução n. 163, de 13 de março de 2014. Dispõe sobre a abusividade do direcionamento de publicidade e de comunicação mercadológica à criança e ao adolescente. Disponível em: <http://pesquisa.in.gov.br/imprensa/jsp/visualiza/index.jsp?jornal=1\&pagina=4\&da ta=04/04/2014>. Acesso em: 31 jan. 2017.

${ }^{11}$ BJURSTRÖM, E. Children and television advertising: a critical Study of international research concerning the effects of TV: commercials on children. Swedish Consumer Agency, 1994.
} 
publicitárias que lhes são dirigidas, por não conseguirem distingui-las da programação na qual são inseridas, tampouco compreender seu caráter persuasivo. Ainda, o Conselho Federal de Psicologia do Brasil ${ }^{12}$ entende que: (a) a publicidade tem maior possibilidade de induzir ao erro as crianças até os 12 anos, quando não possuem todas as ferramentas necessárias para compreender o real; (b) as crianças não têm a mesma capacidade de resistência mental e de compreensão da realidade que um adulto; e (c) as crianças não estão em condições de enfrentar com igualdade de força a pressão exercida pela publicidade no que se refere à questão do consumo.

Portanto, especialistas no tema apontam de forma evidente a condição de desigualdade entre o público infantil e a publicidade a ele dirigida. A criança se mostra munida de poucas defesas diante dos apelos publicitários, em decorrência de sua própria condição de pessoa em desenvolvimento. Resta, então, explícita a condição duplamente peculiar da criança frente aos apelos publicitários: (a) ela é vulnerável devido a seu processo inconcluso de formação física e psíquica e (b) não entende a publicidade como tal, ou seja, seu caráter persuasivo.

Diante disso, o público infantil se revela alvo de fácil convencimento, pois não consegue lidar com a alta complexidade das estratégias empregadas pela publicidade em paridade de condições com quem as cria, nem consegue responder com igualdade à pressão exercida pela comunicação comercial. Identificada tal desigualdade, conclui-se que a efetivação da proibição da publicidade dirigida ao público infantil é algo fundamental para a preservação do direito da criança ao respeito e de sua integridade física, psíquica e moral.

\section{Os impactos sociais da publicidade dirigida à criança}

O Brasil possui uma população de pouco mais de 200 milhões de pessoas ${ }^{13}$, sendo que $29,7 \%$ delas estão na faixa entre zero e 17 anos $^{14}$. O cenário da infância brasileira, infelizmente, indica uma realidade de extrema vulnerabilidade: $29 \%$ da população vive em famílias pobres, mas, entre as crianças, esse número chega a $45,6 \%{ }^{15}$.

A publicidade dirigida ao público de até 12 anos de idade agrava ainda mais esse cenário de vulnerabilidade, por gerar impactos bastante negativos ao desenvolvimento infantil saudável, como o consumismo, a erotização precoce, os transtornos de comportamento, o estresse familiar, o alcoolismo, a violência, a obesidade infantil,

\footnotetext{
${ }^{12}$ CONSELHO FEDERAL DE PSICOLOGIA. A publicidade dirigida ao público infantil: considerações psicológicas, 2008. Disponível em: <http://site.cfp.org.br/wp-content/uploads/2008/10/cartilha_publicidade_infantil. pdf $>$. Acesso em: 31 jan. 2017.

${ }^{13}$ INSTITUTO BRASILEIRO DE GEOGRAFIA E ESTATÍSTICA - IBGE. População brasileira ultrapassa marca de 200 milhões, 2013. Disponível em: <http://g1.globo.com/brasil/noticia/2013/08/populacao-brasileiraultrapassa-marca-de-200-milhoes-diz-ibge.html>. Acesso em: 23 jun. 2016.

${ }^{14}$ INSTITUTO BRASILEIRO DE GEOGRAFIA E ESTATÍSTICA - IBGE. Pesquisa Nacional por Amostra de Domicílios, 2009.

${ }^{15}$ FUNDO das Nações Unidas para a Infância (UNICEF). Infância e adolescência no Brasil, 2014. Disponível em <http://www.unicef.org/brazil/pt/activities.html>. Acesso em: 23 jun. 2016.
} 
dentre outros. É evidente que todas essas consequências da publicidade infantil são multifatoriais, não sendo a publicidade a única causa de seu aparecimento, ainda que desempenhe papel decisivo no agravamento de tais problemas.

No Brasil, a pesquisa mais completa e abrangente acerca do impacto da publicidade infantil nas crianças foi elaborada pela Secretaria Nacional do Consumidor (Senacon) do Ministério da Justiça em parceria com o Grupo de Pesquisa da Relação Infância, Juventude e Mídia da Universidade Federal do Ceará (Grim). Divulgada em abril de 2016, a pesquisa apresenta a perspectiva das crianças acerca da compreensão da natureza da publicidade, da apreciação que elas fazem das estratégias de persuasão nela contidas e os possíveis impactos desse tipo de comunicação em sua formação e em seu bem-estar. A pesquisa comprova uma série de fatos importantes com relação a essa prática no Brasil, como, por exemplo, que as crianças são intensamente expostas à publicidade, mas não reconhecem facilmente a comunicação mercadológica no ambiente virtual, especialmente nos chamados $a_{\text {advergames }}^{16}$. A pesquisa destaca, ainda, que muitas crianças reconheceram a influência da publicidade em seus desejos de compra, identificando os seguintes danos: interrupção do lazer infantil; mal-estar físico; sentimento de frustração associado à compra e/ou à indisponibilidade do produto; acesso a conteúdo impróprio para crianças em comerciais; conflitos familiares associados a desejos de consumo; risco à segurança; prejuízo financeiro; invasão de privacidade; sentimentos de insegurança e medo; sentimento de ansiedade para consumir; e vivência de situações de preconceito associados a padrões relacionais e estéticos, correlatos a fatores étnicos, de gênero e de orientação sexual ${ }^{17}$.

\section{Comunicação mercadológica de produtos alimentícios e consequências negativas à saúde das crianças}

$\mathrm{O}$ direcionamento às crianças de estratégias de comunicação mercadológica de produtos alimentícios industrializados e ultraprocessados ${ }^{18}$, via de regra com altos teores de sódio, gorduras saturadas e trans, açúcares e bebidas de baixo valor nutricional, é associado a seu consumo excessivo e habitual, ao aumento dos pedidos de compra, ao estabelecimento de preferências, à modificação dos hábitos alimentares e a impactos na saúde dos indivíduos.

\footnotetext{
${ }^{16} \mathrm{~J}$ ogos com publicidade camuflada tanto em sites, como em redes sociais.

${ }^{17}$ UNIVERSIDADE FEDERAL DO CEARÁ. Publicidade infantil em tempos de convergência: relatório final. Grim, 2016.

18“Formulações industriais feitas inteiramente ou majoritariamente de substâncias extraídas de alimentos (óleos, gorduras, açúcar, amido, proteínas), derivadas de constituintes de alimentos (gorduras hidrogenadas, amido modificado) ou sintetizadas em laboratório com base em matérias orgânicas como petróleo e carvão (corantes, aromatizantes, realçadores de sabor e vários tipos de aditivos usados para dotar os produtos de propriedades sensoriais atraentes). Técnicas de manufatura incluem extrusão, moldagem, e pré-processamento por fritura ou cozimento". (BRASIL. MINISTÉRIO DA SAÚDE. Secretaria de Atenção à Saúde. Departamento de Atenção Básica. Guia alimentar para a população brasileira. 2. ed. Brasília: Ministério da Saúde, 2014. p. 41).
} 
Além dos tradicionais comerciais televisivos e da inserção de marcas e produtos em conteúdos audiovisuais direcionados ao público infantil, sites de empresas de alimentos expõem as crianças a jogos que associam entretenimento a consumo e, por meio das redes sociais (como YouTube ${ }^{19,20}$, Instagram e Facebook), promovem ao público infantil os últimos lançamentos do mercado.

As ações da indústria de alimentos invadem também os espaços de convivência das crianças, como praças e parques públicos ${ }^{21}$ e escolas ${ }^{22}$. Especialmente nesses casos, além da superexposição do público infantil a marcas e produtos, não raro as ações de marketing de lanches, biscoitos, bolinhos, iogurtes, salgadinhos, refrigerantes e bebidas açucaradas se dão por meio de experiências de entretenimento, que são associadas a atividades sobre educação, esportes, meio ambiente, sustentabilidade, lazer, alimentação e nutrição, e a valores como diversão, felicidade, amizade e bem-estar, sem, no entanto, alertar o público-alvo sobre as características daquilo que é anunciado e os potenciais riscos à saúde.

Não por acaso, no que tange ao consumo alimentar de crianças, suas preferências são dominadas por guloseimas com muita densidade energética e pouca qualidade nutriciona ${ }^{23}$. Pais de crianças que foram entrevistados (85\%) afirmam que peças publicitárias influenciam a escolha alimentar dos filhos ${ }^{24}$. Pesquisas de mercado indicam que alimentos infantis, balas e doces, alimentos em geral e fast food são alguns dos produtos sobre os quais as crianças exercem grande influência

\footnotetext{
${ }^{19}$ Sobre os vídeos divulgados por youtubers mirins em seus canais online por meio dos quais apresentam marcas e produtos, alguns deles enviados pelas empresas para que sejam desembrulhados e, assim, conhecidos pelos fãs, também crianças: DELLA BARBA, Mariana. Empresas são denunciadas por publicidade infantil no Youtube. BBC Brasil em São Paulo, 18 jun. 2016. Disponível em: <http://www.bbc. com/portuguese/brasil-36495888>. Acesso em: 18 jun. 2016.

${ }^{20} \mathrm{O}$ envio de brinquedos a youtubers mirins por empresas, inclusive alimentícias, é objeto de dois inquéritos civis conduzidos pelas Procuradorias de São Paulo e do Rio de Janeiro do Ministério Público Federal. ARCOS Dourados Comércio de Alimentos Ltda. (Mc Donald's). McLanche Feliz "Hora da aventura". Disponível em: <http://criancaeconsumo.org.br/acoes/arcos-dourados-comercio-de-alimentos-Itda-mclanche-feliz-horada-aventura/>. Acesso em: 15 jun. 2016; CRIANÇA e consumo. Disponível em: <http://criancaeconsumo. org.br/acoes/youtubers-mirins/>. Acesso em: 15 jun. 2016.

${ }^{21}$ Inquérito civil instaurado pela Promotoria da Tutela Coletiva dos Direitos da Infância e Juventude de São Paulo investiga ações desenvolvidas pela empresa Bimbo do Brasil Ltda. para a realização de oficinas em parques públicos e centros comerciais para as crianças confeitarem bolinhos da marca Ana Maria. BIMBO do Brasil Ltda. - Bolinhos Ana Maria (dezembro/2015). Disponível em: <http://criancaeconsumo.org.br/ acoes/bimbo-do-brasil-Itda-bolinhos-ana-maria/>. Acesso em: 05 jun. 2016.

${ }^{22} \mathrm{Em}$ 2014, a Procuradoria Regional dos Direitos do Cidadão de São Paulo, do Ministério Público Federal, recomendou o fim dos shows do palhaço Ronald McDonald e de ações semelhantes em escolas de educação infantil e fundamental, públicas e privadas. ARCOS Dourados Comércio de Alimentos Ltda. (Mc Donald's). Show do Ronald (agosto/2013). Disponível em: <http://criancaeconsumo.org.br/acoes/arcos-dourados-comerciode-alimentos-Itda-show-do-ronald- mcdonald/>. Acesso em: 14 jun. 2016. A Defensoria Pública do Estado de São Paulo investiga as ações "Olimpíadas de Reciclagem" e "Reciclar é Show", realizadas em escolas pela marca de refrescos em pó Tang. KRAFT Foods Brasil S.A. (Mondelez Brasil Ltda.). Olimpíadas de Reciclagem e Esquadrão Verde Tang (janeiro/2014). Disponível em: <http://criancaeconsumo.org.br/acoes/kraft-foodsolimpiadas-de-reciclagem-e-esquadrao-verde-tang/>. Acesso em: 14 jun. 2016.

${ }^{23}$ DATAFOLHA. Pesquisa: consumismo na infância. Fev 2010. Disponível em: <https://pt.scribd.com/ doc/137316452/Datafolha-Consumismo-Infantil>. Acesso em: 16 jun. 2016.

${ }^{24}$ Id. Ibid.
} 
na hora das compras, elegendo inclusive suas marcas ${ }^{25}$. A crianças de seis a 11 anos de idade gastam seu dinheiro principalmente com guloseimas (73\%), salgadinhos (47\%), sorvetes (44\%) e bebidas $(29 \%)^{26}$.

Há evidências de que a alimentação inadequada nos primeiros anos de vida pode ter efeitos permanentes no crescimento, no metabolismo e na programação metabólica, gerando predisposição à obesidade e a doenças crônicas não transmissíveis (DCNT) associadas à má alimentação, como diabetes, problemas cardiovasculares, problemas renais, alguns tipos de câncer etc. ${ }^{27}$.

Segundo dados divulgados em 2016 pela Organização Mundial da Saúde (OMS), 41 milhões de crianças com menos de cinco anos de idade no mundo inteiro estavam com sobrepeso ou eram obesas no ano de $2014^{28}$.

No Brasil, segundo a última Pesquisa de Orçamentos Familiares(POF 2008-2009²9), o excesso de peso e a obesidade são encontrados com grande frequência, a partir dos cinco anos de idade, em todos os grupos de renda e em todas as regiões do país, sendo que a faixa etária de cinco a nove anos foi a que apresentou o maior aumento de peso $(33,5 \%)$ em $2008^{30}$. Por outro lado, a pesquisa apontou que o déficit de peso $(4,1 \%)$ entre as crianças nessa faixa etária foi baixo em todas as regiões ${ }^{31}$.

Esses dados revelam um ambiente obesogênico, que dificulta a adoção de escolhas alimentares adequadas e saudáveis por parte dos indivíduos, e um profundo processo de transição nutricional, juntamente com os processos de transição epidemiológica e transição demográfica, em razão de uma rápida mudança de comportamentos alimentares na população como um todo ${ }^{32}$. Nesse sentido, a Pesquisa Nacional de Saúde (PNS) revela que 32,3\% das crianças com menos de dois anos de idade tomam refrigerantes ou suco artificial ${ }^{33}$. E dados do Sistema de Vigilância

${ }^{25}$ NICKELODEON BUSINESS SOLUTION RESEARCH. Pesquisa: 10 segredos para falar com as crianças (Que você esqueceu porque cresceu). 2007. Disponível em: <https://pt.scribd.com/doc/137316961/ Nickelodeon-2>. Acesso em: 17 jun. 2016.

${ }^{26}$ CARTOON NETWORK Pesquisa "Kids Experts". 2007. Disponível em: <https://pt.scribd.com/ doc/137316714/Kids-Expert-Cartoon-Network>. Acesso em: 17 jun. 2016.

${ }^{27}$ TADDEI, José Augusto; TOLONI, Maysa; LONGO-SILVA, Giovana. A publicidade de alimentos dirigida a crianças e a saúde das futuras gerações. In: FONTENELLE, Lais (Org.). Criança e consumo: 10 anos de transformação. São Paulo: Instituto Alana, 2016. p. 179.

${ }^{28}$ Id. Ibid. p. 183.

${ }^{29}$ INSTITUTO BRASILEIRO DE GEOGRAFIA E ESTATÍSTICA - IBGE. Pesquisa de orçamentos familiares no Brasil 2009-2009. Antropometria e Estado Nutricional de Crianças, Adolescentes e Adultos no Brasil. Rio de Janeiro, 2010.

${ }^{30}$ Além disso, $16,6 \%$ do total de meninos e $11,8 \%$ do total de meninas também eram obesos. 0 número de crianças dessa faixa etária com excesso de peso aumentou ao longo de 34 anos: em 2008-09, 34,8\% dos meninos estavam com o peso acima da faixa considerada saudável pela OMS. Em 1989, esse índice era de $15 \%$, contra 10,9\% em 1974-75. Observou-se padrão semelhante nas meninas, que de 8,6\% na década de 1970 foram para 11,9\% no final dos anos 1980 e chegaram aos 32\% em 2008-09 (Id. Ibid.)

${ }^{31}$ Id. Ibid. p. 49.

32TADDEI, José Augusto; TOLONI, Maysa; LONGO-SILVA, Giovana. op. cit., p. 175.

${ }^{33}$ MAIS de 30\% das crianças consomem refrigerante antes dos 2 anos. Disponível em: <http://www.brasil.gov.br/ saude/2015/08/mais-de-30-das-criancas-consomem-refrigerante-antes-dos-2-anos>. Acesso em: 16 jun. 2016. 
Alimentar e Nutricional do Ministério da Saúde indicam que 56\% das crianças entre seis e 23 meses haviam ingerido, em 2015, algum tipo de produto ultraprocessado no dia anterior à consulta pediátrica em Unidades Básicas de Saúde ${ }^{34}$.

Aumenta, assim, o custo do Estado brasileiro com o sistema de saúde pública em todos os níveis de complexidade. Os gastos para o Sistema Único de Saúde (SUS) com internações e tratamentos relacionados à obesidade e DCNT foram estimados em 488 milhões de reais em $2011^{35}$. Se computados os custos com a queda da produtividade, os gastos com sistema de saúde e os investimentos necessários para reduzir os impactos da obesidade, os valores equivaleriam a 2,4\% do PIB brasileiro, ou 110 bilhões de reais, em $2014^{36}$.

Para controlar e reverter essa realidade, medidas regulatórias sobre o marketing desses produtos alimentícios, especialmente para crianças, são compreendidas como necessárias por especialistas da área de saúde pública e organismos internacionais, e estão sendo incorporadas pelos países, como vem acontecendo no Brasil.

\subsection{Panorama global: a atuação da OMS}

Desde o final da década de 1990, as DCNT são reconhecidas pela OMS como a principal causa de morte e incapacidade no mundo todo. Naquele momento, evidências científicas apontavam que o número de pessoas afetadas apresentava rápido crescimento, em diversas regiões do mundo e classes sociais.

A OMS passou a defender ações integradas para reduzir a incidência das principais DCNT - doenças cardiovasculares, câncer, doença pulmonar obstrutiva crônica e diabetes -, focadas em prevenção e controle dos principais fatores de risco, como tabagismo, dietas não saudáveis e pouca atividade física, em todas as instâncias da sociedade, com envolvimento de sociedade civil e governo, entidades privadas e organizações do terceiro setor.

A 51 a Assembleia Mundial de Saúde (1998) reconheceu a ameaça global e a necessidade de implementar uma resposta efetiva no campo das políticas públicas

\footnotetext{
${ }^{34} \mathrm{O}$ consumo de alimentos como hambúrguer ou embutidos, biscoito recheado, macarrão instantâneo e bebidas adoçadas apresentou resultados elevados, com índices de 14\%, 32\%, 27\% e 40\%, respectivamente. CONSUMO alimentar de crianças até dois anos não é adequado. Disponivel em: <http://www.brasil.gov.br/saude/2016/06/consumo-alimentar-de-criancas-ate-dois-anos-nao-eadequado>. Acesso em: 18 jun. 2016.

'LIVEIRA, Michele Lessa de. Estimativa dos custos da obesidade para o Sistema Único de Saúde do Brasil. 2013. Tese (Doutorado) - Faculdade de Ciências da Saúde, Universidade de Brasília, Brasília, 2013. Disponível em: <http://repositorio.unb.br/handle/10482/13323>. Acesso em: 15 jun. 2016.

${ }^{35}$ OLIVEIRA, Michele Lessa de. Estimativa dos custos da obesidade para o Sistema Único de Saúde do Brasil. 2013. Tese (Doutorado) - Faculdade de Ciências da Saúde, Universidade de Brasília, Brasília, 2013. Disponível em: <http://repositorio.unb.br/handle/10482/13323>. Acesso em: 15 jun. 2016.

${ }^{36}$ MCKINSEY GLOBAL INSTITUTE. Overcoming obesity: an initial economic analysis. 2014. Disponível em: <http://www.mckinsey.com/industries/healthcare-systems-and-services/our-insights/how-the-worldcould-better-fight-obesity>. Acesso em 15 jun. 2016.
} 
de saúde e, assim, propôs a elaboração, pela OMS, de uma Estratégia Global para a Prevenção e o Controle das DCNT (Resolução WHA51.18 $\left.{ }^{37}\right)^{38}$.

Em 2002, a 55 a Assembleia Mundial de Saúde, diante do crescimento da taxa de mortalidade atribuída às DCNT, e também em função da transição demográfica e epidemiológica e da globalização econômica em curso, aprovou, dentro do marco da Estratégia para Prevenção e Controle das DCNT, a criação de uma Estratégia Global sobre Dieta, Atividade Física e Saúde (Resolução WHA55.23 ${ }^{39}$ ), endossada dois anos depois pela 57 a Assembleia Mundial de Saúde (Resolução WHA57.17 $7^{40}$ ).

A estratégia reforça o papel dos Estados-Membros de prover informações adequadas aos consumidores para que eles possam exercer escolhas alimentares saudáveis. Também que a publicidade influencia as escolhas alimentares dos indivíduos, que as estratégias de marketing de alimentos e bebidas não devem explorar a credulidade ou a inexperiência das crianças e que os governos deveriam trabalhar em conjunto com grupos de consumidores e com o setor privado ${ }^{41}$ para desenvolver uma abordagem multissetorial adequada para lidar com as ações de marketing, patrocínio, promoção e publicidade ${ }^{42}$.

Entre os anos de 2007 e 2010, ocorreu um processo de acúmulo de evidências científicas, trocas de experiências e consultas com os Estados-Membros da OMS, especialistas e diversos representantes do setor produtivo e da sociedade civil a respeito dos impactos do marketing sobre os hábitos alimentares e a saúde das crianças ${ }^{43}$, bem como as medidas regulatórias naquele momento adotadas pelos países, inclusive o Brasil ${ }^{44}$.

\footnotetext{
${ }^{37}$ WORLD HEALTH ORGANIZATION. WHA51.18. Noncommunicable disease prevention and control. Disponível em: <http://www.who.int/genomics/publications/governance/wha/wha062/en/>. Acesso em: 31 jan. 2017. ${ }^{38}$ No ano 2000, o Relatório Mundial de Saúde estimou que, em 1999, as DCNTs juntas contribuíram para aproximadamente $60 \%$ das mortes no mundo e a $43 \%$ da carga global de doenças. No caso dos países de rendas baixa e média, esses números aumentavam para $79 \%$ de mortes e $85 \%$ da carga de doenças. Em todos os países, essas enfermidades atingiam, principalmente, os segmentos populacionais de menor renda.

${ }^{39}$ WORLD HEALTH ORGANIZATION. WHA55.23. Diet physical activity and health. Disponivel em: <http://apps. who.int/gb/archive/pdf_files/WHA55/ewha5523.pdf?ua=1>. Acesso em: 01 jun. 2016.

${ }^{40}$ WORLD HEALTH ORGANIZATION. WHA57.17. Global strategy on diet, physical activity and health. Disponivel em: <http://apps.who.int/gb/ebwha/pdf_files/WHA57/A57_R17-en.pdf>. Acesso em: 31 jan. 2017.

${ }^{41}$ WORLD HEALTH ORGANIZATION (WHO). Global strategy on diet, physical activity and health. p. 14. Disponivel em: <http://apps.who.int/iris/bitstream/10665/43035/1/9241592222_eng.pdf?ua=1>. Acesso em: 01 jun. 2016.

${ }^{42}$ Id. Ibid., p. 7.

${ }^{43}$ Relatórios técnicos publicados pela OMS em 2007 e 2009 revelam, a partir da revisão de estudos disponíveis naquele momento, que os principais produtos anunciados eram cereais matinais açucarados, refrigerantes, confeitos doces, salgadinhos e redes de fast food e apontam as evidências científicas sobre o impacto das ações de marketing no conhecimento, preferências e escolhas das crianças.

${ }^{44} \mathrm{Em} 2004$, a OMS publicou o estudo Marketing food to children: the global regulatory environment, de autoria da pesquisadora Corinna Hawkes (HAWKES, Corina. Marketing food to children: the global regulatory environment. World Health Organization, 2004). O relatório examinou o ambiente regulatório relativo à publicidade de alimentos para crianças em 73 países, a partir de revisão das leis e dos códigos de autorregulamentação existentes, com atenção especial a seis tipos de estratégias comumente usadas pela indústria de alimentos: publicidades na televisão, na internet, dentro das escolas, patrocínio, product placement e promoções.
} 
Foram identificadas as lacunas existentes, com relação tanto aos tipos de estratégias como aos meios de veiculação e às sanções impostas, o que chamou a atenção para a necessidade de se pensar não apenas em como lidar com a publicidade direcionada às crianças - um dos fatores que contribui para a obesidade infantil, porém não o único -, mas também em como fazê-lo de forma efetiva, o que implicaria assegurar que a saúde fosse colocada no centro do desenvolvimento das políticas públicas ${ }^{45}$, inclusive por meio do suporte da OMS aos países ${ }^{46}$.

Ao longo desse processo, foram identificadas mudanças no cenário regulatório global ${ }^{47}$, como novas estratégias autorregulatórias; lento avanço do tema em alguns países, mesmo com o advocacy de grupos de defesa do consumidor e da saúde pública; desenvolvimento de ações regulatórias especialmente em países desenvolvidos, apesar de o problema estar em visível crescimento nos países de economias média e baixa; mais atenção a outras técnicas publicitárias, e não apenas às campanhas televisivas, e ao monitoramento e à execução das leis, mas com pouca avaliação do impacto da regulação na quantidade e qualidade das publicidades. Além disso, mesmo com medidas regulatórias, havia o crescimento das formas tradicionais de publicidade nos países de baixo e médio desenvolvimento e, em todos os países, o crescimento de modos não tradicionais de marketing.

Além das mudanças, estudos detalham as abordagens adotadas pelos setores envolvidos: a indústria priorizava códigos de autorregulação, continuava anunciando seus produtos por meio de diversas técnicas e fazia lobby contra as propostas legislativas para restringir a publicidade de alimentos para as crianças. Os governos apoiavam a autorregulação, ou medidas regulatórias caso aquela falhasse, e alguns desenvolveram ações regulatórias estatais, sobretudo a respeito das estratégias publicitárias nas escolas. Os grupos de defesa do consumidor realizavam campanhas para apoiar a restrição de qualquer tipo de marketing para crianças que encorajassem a adoção de hábitos não saudáveis.

O amplo debate internacional sobre o tema culminou na elaboração de um relatório para a implementação da Estratégia Global para Prevenção e Controle das DCNT ${ }^{48}$, aprovado em maio de 2010, durante a 63a Assembleia Mundial

\footnotetext{
${ }^{45}$ HAWKES, Corina. op. cit., p. 58.

${ }^{46} \mathrm{Em}$ maio de 2006 foram realizados um fórum e um encontro técnico em Oslo, Noruega, sobre publicidade de alimentos e bebidas para crianças. WHO Forum on the Marketing of Food and Non-alcoholic Beverages to Children (2006 : Oslo, Norway). Marketing of food and non-alcoholic beverages to children: report of a WHO forum and technical meeting, Oslo, Norway, 2-5 May 2006.

${ }^{47} \mathrm{Em}$ 2007, a OMS publicou novo estudo realizado por Corinna Hawkes, com atualizações ocorridas entre 2004 e 2006. HAWKES, C. Marketing Food to Children: Changes in the Global Regulatory Environment 2004-2006. OMS, 2007.

${ }^{48}$ WORLD HEALTH ORGANIZATION (WHO). EB 126/12: Prevention and control of noncommunicable diseases: implementation of the global strategy. 2009. Disponivel em: <http://apps.who.int/gb/ebwha/pdf_files/ EB126/B126_12-en.pdf>. Acesso em: 15 jun. 2016.
} 
de Saúde, por meio da Resolução WHA63.14 sobre marketing de alimentos e bebidas não alcoólicas para crianças ${ }^{49}$. Foi então estabelecido um conjunto de 12 recomendações para orientar os países no processo de desenvolvimento de novas políticas públicas (com distintas abordagens regulatórias), a fim de reduzir a exposição das crianças à publicidade de alimentos com altos teores de gorduras saturadas e trans, açúcares livres ou sódio e seu impacto sobre elas. Além disso, foram incluídos meios para o desenvolvimento, implementação, monitoramento e avaliação desse tipo de publicidade e para o apoio a novas pesquisas. Aos governos é conferido o papel central, com vistas a proteger o interesse público e evitar potenciais conflitos de interesses. Destaca-se a previsão de mecanismos de denúncias e aplicação de sanções ${ }^{50}$, e a delimitação de alguns ambientes livres de publicidade - tais como escolas, inclusive durante atividades recreativas e culturais em seu interior.

\subsection{Panorama regional: a atuação da Organização Pan-Americana da Saúde}

Os debates e processos realizados no nível global geram reflexos no âmbito regional. Com base na Resolução WHA63/14, a Organização Pan-Americana da Saúde (OPAS) lançou, em abril de 2012, o documento Recomendações da consulta de especialistas da Organização Pan-Americana da Saúde sobre a promoção e a publicidade de alimentos e bebidas não alcoólicas para crianças nas américas ${ }^{51}$, fruto do acúmulo de evidências científicas e reuniões com especialistas.

O documento elencou 13 diretrizes, que, em linhas gerais, estabelecem o papel central dos Ministérios da Saúde dos países no processo regulatório de promoção e publicidade de alimentos para crianças (definidas no documento como as pessoas com menos de 16 anos de idade); a necessidade da determinação de consenso sobre o tema dentro dos governos; o envolvimento de outras partes interessadas; e a criação de dispositivos legais para implementar as políticas, além da designação de órgãos para monitorá-las.

Em outubro de 2014, a OPAS lançou também o Plano de Ação para a Prevenção da Obesidade em Crianças e Adolescentes (2014-2019), que define uma

\footnotetext{
${ }^{49}$ WORLD HEALTH ORGANIZATION (WHO). Set of recommendations on the marketing of foods and non-alcoholic beverages to children. Genebra: WHO, 2010.

${ }^{50} \mathrm{Em}$ resposta à Resolução WHA63.14, a OMS publicou, em 2012, o documento $A$ framework for implementing the set of recommendations on the marketing of foods and non-alcoholic beverages to children, com o objetivo de orientar os governos na implementação das recomendações em seus territórios. WORLD HEALTH ORGANIZATION (WHO). A framework for implementing the set of recommendations on the marketing of foods and non-alcoholic beverages to children. Genebra: WHO, 2012.

${ }^{51}$ ORGANIZAÇÃO PAN-AMERICANA DA SAÚDE (OPAS). Recomendações da Consulta de Especialistas da Organização Pan-Americana da Saúde sobre a Promoção e a Publicidade de Alimentos e Bebidas Não Alcoólicas para Crianças nas Américas. Washington, D.C.: OPAS, 2012.
} 
linha de ações estratégicas para ajudar os países a reduzir a obesidade infanto-juvenil e a restringir o marketing, estabelecendo como objetivo "sancionar regulamentações para proteger crianças e adolescentes do impacto da publicidade de bebidas açucaradas, produtos energéticos com poucos nutrientes e fast-food"52.

As medidas adotadas pela OMS e pela OPAS influenciaram, no âmbito regional americano, a incorporação por diversos países - como Chile, Peru, México, Uruguai, Bolívia - da regulação da publicidade de alimentos com foco nas crianças em suas agendas de políticas públicas, com distintas abordagens ${ }^{53}$.

\subsection{Panorama nacional: o Brasil e a regulação da publicidade de alimentos direcionada às crianças}

O Brasil, em conformidade com as discussões e recomendações no âmbito global e regional, incorporou a publicidade de alimentos em sua agenda regulatória, com vistas à proteção da saúde da população e, especialmente, das crianças.

No campo legislativo, há inúmeros projetos de lei tramitando, nos níveis federal, estadual, distrital e municipal, sobre, por exemplo, publicidade de produtos alimentícios no ambiente escolar (inclusive cantinas), anúncios de refrigerantes e combos de alimentos com brinquedos, além de medidas que tratam da publicidade direcionada às crianças de forma mais ampla ${ }^{54,55}$.

No âmbito do Poder Executivo, em 1999 o Ministério da Saúde já apresentava, por meio da Política Nacional de Alimentação e Nutrição (PNAN), uma preocupação com a prevenção e o controle dos distúrbios nutricionais e de doenças associadas à alimentação e nutrição. Assim, em 2003, a então Coordenação-Geral da Política de Alimentação e Nutrição (CGPAN) do Ministério da Saúde elaborou um documento que insere a regulação da publicidade de alimentos infantis como aspecto importante para intervenção do governo brasileiro no campo da saúde pública - em um momento em que, no âmbito global, estava sendo proposta a Estratégia Global sobre Dieta, Atividade Física e Saúde da OMS ${ }^{56}$.

52ORGANIZAÇÃO PAN-AMERICANA DA SAÚDE (OPAS). Plano de ação para prevenção da obesidade em crianças e adolescentes. 2015. p. 21. Disponível em: <http://www.paho.org/bra/images/stories/UTFGCV/ planofactionchildobesity-por.pdf?ua=1>. Acesso em: 17 jun. 2016.

${ }^{53}$ Nesse sentido: CHILE aprova fim da publicidade de alimentos dirigida às crianças. Disponível em: <http:// criancaeconsumo.org.br/noticias/chile-aprova-fim-da-publicidade-de-alimentos-dirigida-as-criancas/>. Acesso em: 15 jun. 2016.

${ }^{54}$ Por exemplo, DF reforça proibição de publicidade nas escolas. Disponível em: <http://criancaeconsumo. org.br/noticias/df-reforca-proibicao-de-publicidade-nas-escolas/>. Acesso em: 15 jun. 2016.

${ }^{55}$ MARTINS, A. P. B. (Org.). Publicidade de alimentos não saudáveis: os entraves e as perspectivas de regulação no Brasil. São Paulo: Instituto Brasileiro de Defesa do Consumidor - Idec, 2014. (Cadernos Idec - Série Alimentos, v. 2).

${ }^{56}$ MINISTÉRIO DA SAÚDE, Secretaria de Atenção à Saúde, Departamento de Atenção Básica, Coordenação-Geral da Política de Alimentação e Nutrição. A promoção da alimentação saudável como instrumento de prevenção e combate ao sobrepeso e obesidade. Disponível em: <http://189.28.128.100/ nutricao/docs/geral/obesidade2004.pdf>. Acesso em 18 jun. 2016. 
Em 2005, a Agência Nacional de Vigilância Sanitária (Anvisa) passou a atuar nessa agenda regulatória. Um grupo de trabalho composto por representantes do poder público, associações empresariais, entidades de defesa dos consumidores e da saúde pública elaborou uma proposta de texto que foi submetida a consulta pública (CP n. 71/2006) em novembro de 2006. A consulta tratava da oferta, propaganda, publicidade, informação e outras práticas correlatas para divulgação ou promoção de alimentos com quantidades elevadas de açúcar, gordura saturada, gordura trans e sódio e de bebidas com baixo teor nutricional. O documento proposto continha regras específicas sobre a proteção da saúde das crianças, estipulando horários permitidos para a veiculação de comerciais para crianças no rádio e na televisão e vendando o uso de personagens do universo infantil, bem como publicidade em escolas ${ }^{57}$.

Após forte movimentação e articulação dos setores contrários e favoráveis à norma, com elaboração de pareceres de renomados juristas encomendados pelo setor produtivo, manifestos encabeçados por organizações da sociedade civil, moções de apoio $^{58}$ e divulgações de novos compromissos de autorregulamentação por empresas do setor alimentício e pelo mercado publicitário, o texto da Resolução da Diretoria Colegiada (RDC) n. 24/2010 59 foi publicado com muitas mudanças, como a exclusão do título sobre a publicidade infantil. De qualquer forma, ainda representava um avanço para os direitos dos consumidores, inclusive por estabelecer necessidade de mensagens de alerta em "em toda e qualquer forma de propaganda, publicidade ou promoção comercial de alimentos com quantidades elevadas de açúcar, de gordura saturada, de gordura trans, de sódio e de bebidas com baixo teor nutricional, direcionada a crianças" (artigo 12) ${ }^{60}$.

No entanto, apesar da importância da iniciativa governamental, coadunada com o que acontecia no âmbito mundial, foram propostas 11 ações judiciais por associações representativas de empresas, contestando a competência da Anvisa e a constitucionalidade de a norma ser implementada ${ }^{61}$.

Outros importantes instrumentos na área de saúde pública e segurança alimentar e nutricional também foram publicados nos últimos anos ressaltando o papel de medidas regulatórias, inclusive legislativas.

\footnotetext{
${ }^{57}$ MARTINS, A. P. B. (Org.). op. cit., p. 17.

${ }^{58}$ Por exemplo, em 2008, o Conselho Nacional de Saúde(CNS) elaboroua Resoluçãon. 408/2008 com recomendações para a promoção da alimentação saudável, reverção da epidemia de obesidade e prevenção das DCNT, fazendo menção expressa à necessidade de proteger o público infantil. CONSELHO NACIONAL DE SAÚDE. Disponível em: <http://conselho.saude.gov.br/ultimas_noticias/2010/img/211_ro/Res0408.pdf>. Acesso em: 16 jun. 2016.

${ }^{59}$ AGÊNCIA NACIONAL DE VIGILÂNCIA SANITÁRIA. Resolução da Diretoria Colegiada n. 24, de 15 de junho de 2010. Dispõe sobre a oferta, propaganda, publicidade, informação e outras práticas correlatas cujo objetivo seja a divulgação e a promoção comercial de alimentos considerados com quantidades elevadas de açúcar, de gordura saturada, de gordura trans, de sódio, e de bebidas com baixo teor nutricional, nos termos desta Resolução, e dá outras providências. Disponível em: <http://portal.anvisa.gov.br/documents/33864/284972/RDC24_10_ Publicidade\%2Bde\%2Balimentos.pdf/c406dOdf-e88b-407a-9c0f-30da652f4a44>. Acesso em: 31 jan. 2017.

${ }^{60}$ Id. Ibid.

${ }^{61}$ CONSULTA Pública n. 71 - ANVISA. Disponível em: <http://criancaeconsumo.org.br/executivo/consultapublica-anvisa-no-71/>. Acesso em: 19 fev. 2017.
} 
O Plano de Ações Estratégicas para o Enfrentamento das Doenças Crônicas não Transmissíveis (2011-2022) ${ }^{62}$ identifica doenças do aparelho circulatório, câncer, doenças respiratórias crônicas e diabetes como responsáveis por $72 \%$ das mortes no Brasil e elenca a necessidade de restrições ao marketing de alimentos e bebidas com excesso de sódio, gorduras e açúcar, especialmente para crianças, por meio do fortalecimento da regulamentação e do apoio à aprovação de leis no Congresso Nacional.

A nova edição da PNAN $(2012)^{63}$ reforça, por exemplo, em sua diretriz que trata de controle e regulação dos alimentos, a importância do monitoramento da publicidade de alimentos a fim de aperfeiçoar o direito à informação e proteger o consumidor de práticas potencialmente abusivas.

O primeiro Plano Nacional de Segurança Alimentar e Nutricional (Plansan), vigente entre 2012 e $2015^{64}$ e elaborado pela Câmara Interministerial de Segurança Alimentar e Nutricional (Caisan), tinha entre seus objetivos "controlar e prevenir os agravos e doenças consequentes da insegurança alimentar e nutricional" e "promover o controle e a regulação de alimentos". O plano atual (2016-2019), prevê o monitoramento de projetos de lei sobre publicidade de alimentos, inclusive em cantinas escolares e a "regulamentação da propaganda, publicidade e promoção comercial de alimentos e bebidas processados e ultraprocessados em equipamentos das redes de educação e saúde, públicos e privados, equipamentos de assistência social e órgãos públicos" 65 .

Importante mencionar, ainda, a nova edição do Guia Alimentar da População Brasileira, lançada em 2014, e que aponta, entre os obstáculos à alimentação saudável que devem ser compreendidos para serem superados, a publicidade de alimentos especialmente direcionada ao público infantil ${ }^{66}$.

\section{A regulação da publicidade infantil no Brasil e as bebidas e alimentos}

Ainda que sejam importantes as medidas específicas sobre a regulação da publicidade de alimentos e bebidas consideráveis não saudáveis direcionada a crianças, sobretudo diante dos graves problemas de saúde pública, é preciso ressaltar que,

\footnotetext{
${ }^{62}$ BRASIL. MINISTÉRIO DA SAÚDE. Secretaria de Vigilância em Saúde. Departamento de Análise de Situação de Saúde. Plano de ações estratégicas para o enfrentamento das doenças crônicas não transmissíveis (DCNT) no Brasil: 2011-2022. Brasília: Ministério da Saúde, 2011.

${ }^{63}$ BRASIL. MINISTÉRIO DA SAÚDE. Secretaria de Atenção à Saúde. Departamento de Atenção Básica. Política Nacional de Alimentação e Nutrição. Brasília: Ministério da Saúde, 2012.

${ }^{64}$ CAISAN. Câmara Interministerial de Segurança Alimentar e Nutricional. Plano Nacional de Segurança Alimentar e Nutricional: 2012/2015. Brasília: CAISAN, 2011.

${ }^{65}$ CONSELHO FEDERAL DE NUTRICIONISTAS. Plano Nacional de SAN. Disponível em: <http://www.cfn.org.br/ wp-content/uploads/2016/05/PLANSAN-2016.pdf>. Acesso em: 16 jun. 2016.

${ }^{66}$ BRASIL. MINISTÉRIO DA SAÚDE. Secretaria de Atenção à Saúde. Departamento de Atenção Básica. Guia alimentar para a população brasileira., cit.
} 
no Brasil, a prática do direcionamento de publicidade de qualquer produto ou serviço ao público infantil já pode ser considerada ilegal. Assim, a publicidade infantil de alimentos e bebidas também já pode ser considerada uma prática proibida.

O entendimento da proibição da publicidade infantil, inclusive de alimentos e bebidas, no Brasil parte de uma interpretação sistemática da $\mathrm{CF} / 88$, do Estatuto da Criança e do Adolescente (ECA, Lei n. 8.069/199067), da Convenção das Nações Unidas sobre as Crianças (Decreto n. 99.710/1990 ${ }^{68}$ ), do Código de Defesa do Consumidor (CDC, Lei n. 8.078/1990 $0^{69}$ ) e da Resolução n. 163 de 13 de março de 2014, publicada no Diário Oficial da União em 4 de abril de 2014, do Conselho Nacional dos Direitos da Criança e do Adolescente (Conanda) ${ }^{70}$. Nesse sentido, entende Vidal Serrano Jr:

Assim, toda e qualquer publicidade dirigida ao público infantil parece inelutavelmente maculada de ilegalidade, quando menos por violação de tal ditame legal. (...) Posto o caráter persuasivo da publicidade, a depender do estágio de desenvolvimento da criança, a impossibilidade de captar eventuais conteúdos informativos, quer nos parecer que a publicidade comercial dirigida ao público infantil esteja, ainda uma vez, fadada ao juízo de ilegalidade. Com efeito, se não pode captar eventual conteúdo informativo e não tem defesas emocionais suficientemente formadas para perceber os influxos de conteúdos persuasivos, praticamente em todas as situações, a publicidade comercial dirigida a crianças estará a se configurar como abusiva e, portanto, ilegal ${ }^{71}$.

Tanto o artigo 227 da CF/88 como os dispositivos do ECA (em especial, os artigos $4^{\circ}, 5^{\circ}, 6^{\circ}, 7^{\circ}, 17,18$ e 53) estabelecem o dever da família, da sociedade e do Estado de assegurar com absoluta prioridade à criança os direitos à vida, à saúde, à alimentação, à educação, ao lazer, à profissionalização, à cultura, à dignidade, ao respeito, à liberdade e à convivência familiar e comunitária. Também determina que todas as crianças devem ser protegidas de qualquer forma de negligência, discriminação, exploração, violência, crueldade e opressão.

A Convenção das Nações Unidas sobre os Direitos das Crianças também determina que o tratamento jurídico dispensado a crianças seja balizado pelos parâmetros de direitos humanos e norteadores da proteção integral e do melhor interesse da criança.

\footnotetext{
${ }^{67}$ BRASIL. Lei n. 8.069, de 13 de julho de 1990, cit.

${ }^{68}$ Id. Ibid.

${ }^{69}$ BRASIL. Lei $n$. 8.078, de 11 de setembro de 1990, cit.

${ }^{70}$ SECRETARIA ESPECIAL DE DIREITOS HUMANOS. Resolução n. 163. Disponível em: <http://dh.sdh.gov.br/ download/resolucoes-conanda/res-163.pdf>. Acesso em: 24 jun. 2016.

${ }^{71}$ SERRANO JUNIOR, V. A publicidade comercial dirigida ao público infantil. In: MARTINS, Ives Gandra; REZEK, Francisco (Coords.). Constituição Federal: avanços, contribuições e modificações no processo democrático brasileiro. São Paulo: Ed. Revista dos Tribunais; CEI - Centro de Extensão Universitária, 2008. p. 845-846.
} 
Especificamente com relação à regulação da publicidade no ordenamento jurídico brasileiro, destaca-se que ela é feita pelo CDC e detalhada, no caso da publicidade infantil, pela Resolução n. $163^{72}$ do Conanda, que incorporam a prioridade absoluta, a proteção especial e o melhor interesse da criança ao sistema protetivo dos direitos dos consumidores.

Para as normas que regulam as relações de consumo no Brasil as crianças são presumidamente hipervulneráveis, ou hipossuficientes segundo conceito empregado anteriormente pela doutrina consumerista. Com esse entendimento, Antônio Herman de Vasconcellos e Benjamin assevera:

\begin{abstract}
A hipossuficiência pode ser físico-psíquica, econômica ou meramente circunstancial. O Código, no seu esforço enumerativo, mencionou expressamente a proteção especial que merece a criança contra os abusos publicitários. O Código menciona, expressamente, a questão da publicidade que envolva a criança como uma daquelas a merecer atenção especial. É em função do reconhecimento dessa vulnerabilidade exacerbada (hipossuficiência, então) que alguns parâmetros especiais devem ser traçados ${ }^{73}$.
\end{abstract}

Especificamente sobre o conceito de abusividade na publicidade, o artigo 37 do CDC determina que toda publicidade abusiva é ilegal, e seu parágrafo $2^{\circ}$ estabelece que a publicidade não pode se aproveitar da deficiência de julgamento e experiência da criança, sob pena de ser considerada abusiva e, portanto, ilegal.

Ainda, no artigo 36 do CDC é expresso o princípio da identificação da mensagem publicitária, segundo o qual esta deve ser de fácil e imediata compreensão. Ressalta-se que a publicidade dirigida ao público infantil não atende a esse princípio, tendo em vista que o público com menos de 12 anos possui maior dificuldade para compreensão da publicidade como tal e, ainda, o caráter persuasivo desse tipo de publicidade, conforme exposto anteriormente.

Destaca-se também o artigo 39, inciso IV, do CDC, que proíbe ao fornecedor, como prática abusiva, valer-se da "fraqueza ou ignorância do consumidor, tendo em vista sua idade, saúde, conhecimento ou condição social, para impingir-lhe seus produtos ou serviços" ${ }^{\prime \prime}$.

Pela análise dos artigos do CDC e do entendimento firmado pela psicologia de que a criança até os 12 anos de idade não reconhece a publicidade como tal e não entende seu caráter persuasivo, muitos juristas afirmam que a publicidade infantil

\footnotetext{
${ }^{72}$ CONSELHO NACIONAL DOS DIREITOS DA CRIANÇA E DO ADOLESCENTE. Resolução n. 163, de 13 de março de 2014, cit.

${ }^{73}$ BENJAMIN, A. H. V. et al. Código Brasileiro de Defesa do Consumidor comentado pelos autores do Anteprojeto. Rio de Janeiro: Forense, 2007, p. 299-300.

${ }^{74}$ BRASIL. Lei n. 8.078, de 11 de setembro de 1990, cit.
} 
já é proibida no Brasil por se utilizar da vulnerabilidade da criança e ser, por isso, intrinsicamente abusiva.

Além disso, com o objetivo de reforçar e detalhar o caráter de abusividade e ilegalidade da publicidade direcionada ao público infantil, a Resolução n. 163 do Conanda definiu critérios para identificação das estratégias de publicidade e comunicação mercadológica infantis, detalhando o conceito de abusividade a partir do princípio da proteção integral da criança e dos limites legais previstos no CDC, especialmente nos artigos 36 e 37 , caput e parágrafo $2^{\circ}$.

A Resolução n. 163 do Conanda dá ao aplicador da lei elementos de interpretação diante do caso concreto da abusividade da publicidade dirigida à criança, como bem entende Bruno Miragem, em parecer que conclui pela constitucionalidade da norma ${ }^{75}$.

Destaca-se, ainda, que o fato de as pessoas menores de 16 anos de idade não serem autorizadas a praticar todos os atos da vida civil (por exemplo, os contratos) reflete a situação da criança de impossibilidade de se autodeterminar perante terceiros. Isso, no entanto, não significa que essa pessoa tenha menos direitos, mas, ao contrário, a legislação lhe garante mais proteções exatamente para preservar essa fragilidade temporária da criança.

Munido desses fundamentos jurídicos, que tratam de forma ampla a publicidade direcionada diretamente à criança, e, por conseguinte, também das ações promovidas pela indústria de alimentos, o Superior Tribunal de Justiça (STJ), em março de 2016, ao julgar o Recurso Especial n. $1.558 .086^{76}$ a respeito de publicidade infantil veiculada por uma empresa do setor alimentício, entendeu pela abusividade - e, portanto, ilegalidade - tanto da publicidade televisiva focada no público infantil (artigo 37, parágrafo $2^{\circ}, \mathrm{CDC}$ ) como da venda casada configurada pela oferta de brinquedos com alimentos (artigo 39, inciso I, CDC), abrindo um precedente jurisprudencial paradigmático ${ }^{77}$.

\section{Considerações Finais}

No Brasil, a legislação determina que o direcionamento de publicidade à criança, de qualquer bem e em qualquer meio ou veículo de comunicação, é uma prática abusiva e, portanto, ilegal, o que foi confirmado pela recente decisão do Superior Tribunal de Justiça, em caso específico envolvendo produto alimentício.

\footnotetext{
${ }^{75}$ MIRAGEM, B. A Constitucionalidade da Resolução 163 do Conanda. Instituto Alana, 2014.

${ }^{76}$ Recurso Especial n. 1.558.086. Relator: Ministro Humberto Martins. Recorrente: Pandurata Alimentos. Recorrido: Ministério Público do Estado de São Paulo. D.j. 10.3.2016. Acórdão publicado em: 15.4.2016.

${ }^{77}$ STJ mantém condenação de empresa por publicidade infantil indevida. Disponível em: <http://portal.trt15. jus.br/web/trabalhoinfantil/noticias/-/asset_publisher/5dRN5c2uOPbA/content/stj-mantem-condenacaode-empresa-por-publicidade-infantil-indevi-1;jsessionid=4F2176B05F42AB1038CDE317F5445F13.Ir1>. Acesso em: 19 fev. 2017.
} 
No entanto, o que se vê - não apenas no Brasil, mas no mundo todo - é a visão da criança, por alguns segmentos, como público-alvo, consumidora atual e futura e promotora de vendas perante suas famílias e seus pares. Assim, o mercado de anunciantes, publicitários e meios de comunicação, de maneira sistemática e fundado em interesses exclusivamente econômicos, descumpre o ordenamento jurídico brasileiro e contesta a validade das normas protetivas da infância com frágeis argumentos que alegam suposta censura, paternalismo estatal indevido ou até mesmo a responsabilidade exclusiva da família sobre o cuidado das crianças.

Percebe-se que as discussões no âmbito global, regional e nacional, ocorridas sobretudo nas duas últimas décadas, sobre a publicidade infantil de produtos alimentícios e bebidas de baixo valor nutricional revelam avanços na compreensão dos riscos da exploração da infância, especialmente para a saúde pública. Mas também revelam lacunas e dificuldades, inclusive no tocante à definição das características nutricionais dos produtos que poderiam ser anunciados ou não, o que é percebido pelos movimentos de pressão e resistência, por parte de representantes dos Estados, empresas e entidades da sociedade civil.

Proteger a saúde da criança é fundamental, e isso envolve não apenas seu aspecto físico, mas também psíquico. Portanto, do ponto de vista jurídico e com um olhar mais amplo sobre os impactos do estímulo ao consumismo na infância relacionado com uma ampla gama de produtos, serviços e técnicas publicitárias, o caminho mais adequado deve ser a regulação efetiva da publicidade direcionada às crianças. Isso significa, por um lado, o cumprimento das leis atualmente vigentes e sua efetiva fiscalização pelos órgãos públicos competentes na defesa dos direitos de crianças e consumidores; e, por outro, a elaboração de regras mais específicas, fundamentadas no arcabouço jurídico existente, que não deve, em hipótese alguma, sofrer retrocessos. O olhar prioritário deve estar na criança e em seu peculiar processo de desenvolvimento.

Certamente, as crianças não estão isoladas do restante do mundo e lhes deve ser permitido viver em um ambiente promotor de escolhas saudáveis, desde o princípio de suas vidas. A proibição da publicidade para o público infantil deve, certamente, dialogar com outras agendas regulatórias, focadas em primeiro lugar em proteger o interesse público e o direito à informação, à saúde e à alimentação adequada, garantidos em nossa Constituição Federal e legislação infraconstitucional. Essas agendas dizem respeito, por exemplo, à segurança alimentar e nutricional, à preservação ambiental e à promoção de atividades físicas, o que inclui o respeito ao direito de as crianças brincarem livremente, inclusive nos espaços urbanos.

Para que avanços aconteçam, é fundamental a sensibilização de todos os atores diretamente envolvidos - agentes do poder público, empresas, famílias, educadores, pesquisadores - e, portanto, da sociedade como um todo, sobre a prioridade absoluta dos direitos das crianças, inclusive nas relações de consumo. 


\section{Referências}

ARCOS Dourados Comércio de Alimentos Ltda. (Mc Donald's). McLanche Feliz "Hora da aventura". Disponível em: <http://criancaeconsumo.org.br/acoes/arcos-dourados-comerciode-alimentos-ltda-mclanche-feliz-hora-da-aventura/>. Acesso em: 15 jun. 2016.

Show do Ronald (agosto/2013). Disponível em: <http://criancaeconsumo.org.br/ acoes/arcos-dourados-comercio-de-alimentos-ltda-show-do-ronald-mcdonald/>. Acesso em: 14 jun. 2016.

BENJAMIN, A. H. V. et al. Código Brasileiro de Defesa do Consumidor comentado pelos autores do Anteprojeto. Rio de Janeiro: Forense, 2007.

BIMBO do Brasil Ltda. - Bolinhos Ana Maria (dezembro/2015). Disponível em: <http:// criancaeconsumo.org.br/acoes/bimbo-do-brasil-ltda-bolinhos-ana-maria/>. Acesso em: 05 jun. 2016.

BJURSTRÖM, E. Children and television advertising: a critical Study of international research concerning the effects of TV: commercials on children. Swedish Consumer Agency, 1994.

BRASIL. MINISTÉRIO DA SAÚDE. Secretaria de Atenção à Saúde. Departamento de Atenção Básica. Política Nacional de Alimentação e Nutrição. Brasília: Ministério da Saúde, 2012.

Secretaria de Atenção à Saúde. Departamento de Atenção Básica. Guia alimentar para a população brasileira. 2. ed. Brasília: Ministério da Saúde, 2014.

. Secretaria de Atenção à Saúde. Departamento de Atenção Básica. Política Nacional de Alimentação e Nutrição. Brasília: Ministério da Saúde, 2012.

. Secretaria de Vigilância em Saúde. Departamento de Análise de Situação de Saúde. Plano de ações estratégicas para o enfrentamento das doenças crônicas não transmissíveis (DCNT) no Brasil: 2011-2022. Brasília: Ministério da Saúde, 2011.

. Secretaria de Vigilância em Saúde. Departamento de Análise de Situação de Saúde. Plano de ações estratégicas para o enfrentamento das doenças crônicas não transmissíveis (DCNT) no Brasil: 2011-2022. Brasília: Ministério da Saúde, 2011.

CAISAN. Câmara Interministerial de Segurança Alimentar e Nutricional. Plano Nacional de Segurança Alimentar e Nutricional: 2012/2015. Brasília: CAISAN, 2011.

CARTOON NETWORK Pesquisa "Kids Experts". 2007. Disponível em: <https://pt.scribd. com/doc/137316714/Kids-Expert-Cartoon-Network>. Acesso em: 17 jun. 2016.

CHILE aprova fim da publicidade de alimentos dirigida às crianças. Disponível em: $<$ http:// criancaeconsumo.org.br/noticias/chile-aprova-fim-da-publicidade-de-alimentos-dirigidaas-criancas/>. Acesso em: 15 jun. 2016.

CONSELHO FEDERAL DE NUTRICIONISTAS. Plano Nacional de SAN. Disponível em: $<$ http://www.cfn.org.br/wp-content/uploads/2016/05/PLANSAN-2016.pdf>. Acesso em: 16 jun. 2016. 
CONSELHO FEDERAL DE PSICOLOGIA. A publicidade dirigida ao público infantil: considerações psicológicas, 2008. Disponível em: <http://site.cfp.org.br/wp-content/ uploads/2008/10/cartilha_publicidade_infantil.pdf $>$.

CONSELHO NACIONAL DE SAÚDE. Disponível em: <http://conselho.saude.gov.br/ ultimas_noticias/2010/img/211_ro/Reso408.pdf>. Acesso em: 16 jun. 2016.

CONSUMO alimentar de crianças até dois anos não é adequado. Disponivel em: <http:// www.brasil.gov.br/saude/2016/06/consumo-alimentar-de-criancas-ate-dois-anos-nao-eadequado $>$. Acesso em: 18 jun. 2016.

CONSULTA Pública n. 71 - ANVISA. Disponível em: <http://criancaeconsumo.org.br/ executivo/consulta-publica-anvisa-no-71/>. Acesso em: 19 fev. 2017.

CRIANÇA e consumo. Disponível em: <http://criancaeconsumo.org.br/acoes/youtubersmirins/>. Acesso em: 15 jun. 2016.

DATAFOLHA. Pesquisa: consumismo na infância. Fev 2010. Disponível em: <https://pt.scribd. com/doc/137316452/Datafolha-Consumismo-Infantil>. Acesso em: 16 jun. 2016.

DELLA BARBA, Mariana. Empresas são denunciadas por publicidade infantil no Youtube. BBC Brasil em São Paulo, 18 jun. 2016. Disponível em: <http://www.bbc.com/portuguese/ brasil-36495888>. Acesso em: 18 jun. 2016.

DF reforça proibição de publicidade nas escolas. Disponível em: <http://criancaeconsumo. org.br/noticias/df-reforca-proibicao-de-publicidade-nas-escolas/>. Acesso em: 15 jun. 2016.

FUNDO das Nações Unidas para a Infância (UNICEF). Infância e adolescência no Brasil, 2014. Disponível em <http://www.unicef.org/brazil/pt/activities.html>. Acesso em: 23 jun. 2016.

HAWKES, C. Marketing food to children: changes in the global regulatory environment 2004-2006. OMS, 2007.

HAWKES, C. Marketing food to children: the global regulatory environment. OMS, 2004.

INSTITUTO BRASILEIRO DE GEOGRAFIA E ESTATÍSTICA - IBGE. Pesquisa Nacional por Amostra de Domicílios, 2009.

INSTITUTO BRASILEIRO DE GEOGRAFIA E ESTATÍSTICA - IBGE. Pesquisa de orçamentos familiares no Brasil 2009-2009. Antropometria e Estado Nutricional de Crianças, Adolescentes e Adultos no Brasil. Rio de Janeiro, 2010.

INSTITUTO BRASILEIRO DE GEOGRAFIA E ESTATÍSTICA - IBGE. População brasileira ultrapassa marca de 200 milhões, 2013. Disponível em: <http://g1.globo.com/brasil/noticia/2013/08/ populacao-brasileira-ultrapassa-marca-de-200-milhoes-diz-ibge.html>. Acesso em: 23 jun. 2016.

INSTITUTO BRASILEIRO DE OPINIÃO E ESTATÍSTICA - IBOPE. Mediabook Brasil, Abertura, 2013. Disponível em: http://www.mediabook.ibope.com/pais/brasil/2013/abertura/ destaque. Acesso em: 19 fev. 2017. 
JENKINS, H. Cultura da convergência: a colisão entre os velhos e novos meios de comunicação. São Paulo: Ed. Aleph, 2008.

KRAFT Foods Brasil S.A. (Mondelez Brasil Ltda.). Olimpíadas de Reciclagem e Esquadrão Verde Tang (janeiro/2014). Disponível em: <http://criancaeconsumo.org.br/acoes/kraft-foodsolimpiadas-de-reciclagem-e-esquadrao-verde-tang/>. Acesso em: 14 jun. 2016.

LIPOVETSKY, G. A felicidade paradoxal: ensaios sobre a sociedade de hiperconsumo. São Paulo: Companhia das Letras, 2006.

MAIS de 30\% das crianças consomem refrigerante antes dos 2 anos. Disponível em: $<$ http:// www.brasil.gov.br/saude/2015/08/mais-de-30-das-criancas-consomem-refrigerante-antesdos-2-anos>. Acesso em: 16 jun. 2016.

MARTINS, A. P. B. (Org.). Publicidade de alimentos não saudáveis: os entraves e as perspectivas de regulação no Brasil. São Paulo: Instituto Brasileiro de Defesa do Consumidor - Idec, 2014. (Cadernos Idec - Série Alimentos, v. 2).

MCKINSEY GLOBAL INSTITUTE. Overcoming obesity: an initial economic analysis. 2014. Disponível em: <http://www.mckinsey.com/industries/healthcare-systems-and-services/ our-insights/how-the-world-could-better-fight-obesity>. Acesso em 15 jun. 2016.

MINISTÉRIO DA SAÚDE, Secretaria de Atenção à Saúde, Departamento de Atenção Básica, Coordenação-Geral da Política de Alimentação e Nutrição. A promoção da alimentação saudável como instrumento de prevenção e combate ao sobrepeso e obesidade. Disponível em: <http://189.28.128.100/nutricao/docs/geral/obesidade2004.pdf>. Acesso em 18 jun. 2016.

MIRAGEM, B. A Constitucionalidade da Resolução 163 do Conanda. Instituto Alana, 2014.

NICKELODEON BUSINESS SOLUTION RESEARCH. Pesquisa: 10 segredos para falar com as crianças (Que você esqueceu porque cresceu). 2007. Disponível em: <https://pt.scribd. com/doc/137316961/Nickelodeon-2>. Acesso em: 17 jun. 2016.

OLIVEIRA, Michele Lessa de. Estimativa dos custos da obesidade para o Sistema Único de Saúde do Brasil. 2013. Tese (Doutorado) - Faculdade de Ciências da Saúde, Universidade de Brasília, Brasília, 2013. Disponível em: <http://repositorio.unb.br/handle/10482/13323>. Acesso em: 15 jun. 2016.

ORGANIZAÇÃO PAN-AMERICANA DA SAÚDE (OPAS). Plano de ação para prevenção da obesidade em crianças e adolescentes. 2015. Disponível em: <http://www.paho.org/ bra/images/stories/UTFGCV/planofactionchildobesity-por.pdf?ua=1>. Acesso em: 17 jun. 2016.

. Recomendações da Consulta de Especialistas da Organização Pan-Americana da Saúde sobre a Promoção e a Publicidade de Alimentos e Bebidas Não Alcoólicas para Crianças nas Américas. Washington, D.C.: OPAS, 2012.

POSTMAN, N. O desaparecimento da infância. São Paulo: Granphia, 1994. 
SERRANO JUNIOR, V. A publicidade comercial dirigida ao público infantil. In: MARTINS, Ives Gandra; REZEK, Francisco (Coords.). Constituição Federal: avanços, contribuições e modificações no processo democrático brasileiro. São Paulo: Ed. Revista dos Tribunais; CEI - Centro de Extensão Universitária, 2008. p. 845-846.

STJ mantém condenação de empresa por publicidade infantil indevida. Disponível em: $<\mathrm{http}: / /$ portal.trt15.jus.br/web/trabalhoinfantil/noticias/-/asset_publisher/5dRN5c2u0PbA/content/ stj-mantem-condenacao-de-empresa-por-publicidade-infantil-indevi-1;jsessionid $=4 \mathrm{~F} 2176 \mathrm{~B}$ 05F42AB1038CDE317F5445F13.lr1>. Acesso em: 19 fev. 2017.

TADDEI, José Augusto; TOLONI, Maysa; LONGO-SILVA, Giovana. A publicidade de alimentos dirigida a crianças e a saúde das futuras gerações. In: FONTENELLE, Lais (Org.). Criança e consumo: 10 anos de transformação. São Paulo: Instituto Alana, 2016.

TEMPO de crianças e adolescentes assistindo TV aumenta em 10 anos. Disponível em: <http:// criancaeconsumo.org.br/noticias/tempo-diario-de-criancas-e-adolescentes-em-frente-a-tvaumenta-em-10-anos/>. Acesso em: 12 jun. 2016.

UNIVERSIDADE FEDERAL DO CEARÁ. Publicidade infantil em tempos de convergência: relatório final. Grim, 2016.

WHO Forum on the Marketing of Food and Non-alcoholic Beverages to Children (2006: Oslo, Norway). Marketing of food and non-alcoholic beverages to children: report of a WHO forum and technical meeting, Oslo, Norway, 2-5 May 2006.

WORLD HEALTH ORGANIZATION (WHO). A framework for implementing the set of recommendations on the marketing of foods and non-alcoholic beverages to children. Genebra: WHO, 2012.

.EB 126/12: Prevention and control of noncommunicable diseases: implementation of the global strategy. 2009. Disponível em: <http://apps.who.int/gb/ebwha/pdf_files/EB126/ B126_12-en.pdf>. Acesso em: 15 jun. 2016.

Global strategy on diet, physical activity and health. Disponível em: <http://apps. who.int/iris/bitstream/10665/43035/1/9241592222_eng.pdf?ua=1>. Acesso em: 01 jun. 2016.

Set of recommendations on the marketing of foods and non-alcoholic beverages to children. Genebra: WHO, 2010. 
Hartung P. A. D., Karageorgiadis E. V.

Pedro Affonso Duarte Hartung - Doutorando em Direito do Estado pela Faculdade de Direito da Universidade de São Paulo; especialista em Fundamentos do Direito Alemão pela Universidade Ludwig Maximilians de Munique (Alemanha). Conselheiro do Conselho Nacional dos Direitos da Criança e do Adolescente (2012-2016). Advogado. São Paulo/SP, Brasil.

Ekaterine Valente Karageorgiadis - Mestranda em Saúde Pública da Faculdade de Saúde Pública da Universidade de São Paulo; especialista em Direito do Consumidor pela Escola Paulista de Magistratura; graduada em Direito pela Universidade de São Paulo. Conselheira do Conselho Nacional de Segurança Alimentar e Nutricional. Advogada. São Paulo/SP, Brasil. E-mail: ekaterine.karageorgiadis@usp.br. 